\title{
A Solvent-Free Protocol for the Green Synthesis of 5-Arylidene-2,4-thiazolidinediones Using Ethylenediamine Diacetate as Catalyst
}

\author{
Yuliang Zhang and Zhongqiang Zhou \\ Key Laboratory of Catalysis and Materials Science of the State Ethnic Affairs Commission and Ministry of Education, \\ College of Chemistry and Materials Science, South-Central University for Nationalities, Hubei Province, Wuhan 430074, China \\ Correspondence should be addressed to Zhongqiang Zhou, zhou-zq@hotmail.com
}

Received 11 March 2012; Accepted 28 May 2012

Academic Editor: William N. Setzer

Copyright ( $) 2012$ Y. Zhang and Z. Zhou. This is an open access article distributed under the Creative Commons Attribution License, which permits unrestricted use, distribution, and reproduction in any medium, provided the original work is properly cited.

A simple and efficient synthesis of 5-arylidene-2,4-thiazolidinediones by the Knoevenagel condensation of aromatic aldehydes with 2,4-thiazolidinedione catalyzed by ethylenediamine diacetate under solvent-free conditions is described. The major advantages of this method are simple experimental and work-up procedures, solvent-free reaction conditions, small amount of catalyst, short reaction time, high yields, and utilization of an inexpensive and reusable catalyst.

\section{Introduction}

2,4-Thiazolidinedione and its derivatives exhibit a variety of pharmacological activities [1-3]. 5-Arylidene derivatives of 4-thiazolidinones have been found to be better fungistatic agents than the parent 4-thiazolidinones [4]. It was reported that 5-arylidene-2,4-thiazolidinediones can act as potentially promising aldose reductase inhibitors [5] and 15hydroxyprostaglandin dehydrogenase inhibitors [6]. There is a great interest in 5-benzylidenethiazolidine-2,4-dione derivatives as promising inhibitors of MurD ligase [7]. Thus, the synthesis of 5-arylidene-2,4-thiazolidinediones is currently of much importance. There are several methods reported in the literature for the synthesis of 5-arylidene2,4-thiazolidinediones such as sodium acetate in acetic acid under reflux conditions [8], sodium acetate in acetic acid under microwave irradiation [9], piperidine in ethanol under reflux conditions $[5,10-12]$, piperidinium acetate in toluene under reflux conditions $[6,13]$, piperidinium acetate in ethanol under microwave irradiation [7], piperidinium acetate in DMF under microwave irradiation [14], glycine and sodium carbonate in $\mathrm{H}_{2} \mathrm{O}$ under reflux conditions [15], grinding with ammonium acetate in the absence of solvents [16], $\mathrm{KAl}\left(\mathrm{SO}_{4}\right)_{2} \cdot 12 \mathrm{H}_{2} \mathrm{O}$ in $\mathrm{H}_{2} \mathrm{O}$ at $90^{\circ} \mathrm{C}$ [17], baker's yeast

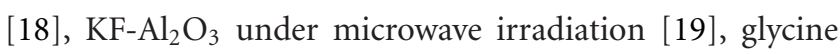
under microwave irradiation [20], and polyethylene glycol300 at $100-120^{\circ} \mathrm{C}$ [21]. Recently, ionic liquids ([bnmim] Cl, $\left.\mathrm{C}_{3}[\mathrm{~min}]_{2} \cdot 2\left[\mathrm{Br}^{-}\right]\right)$catalyzed synthesis of 5 -arylidene-2,4thiazolidinediones have also been reported [22, 23]. Each of these methods have their own advantages but also suffer from one or more disadvantages such as long reaction times, low to moderate yields, tedious work-up procedures, requirement of special apparatus, use of organic solvents, requirement of excess of catalysts, and difficulty in recovery and reusability of the catalysts. Researches are still in progress to improve the preparation methods of 5-arylidene-2,4-thiazolidinediones.

In recent past, ethylenediamine diacetate (EDDA) has emerged as an inexpensive and effective Brönsted acid-base combined salt catalyst in various organic transformations [24-27]. To the best of our knowledge, EDDA has not been used as a catalyst for the synthesis of 5-arylidene-2,4thiazolidinediones and attracted our attention to investigate the application of EDDA as a catalyst. The solvent-free reaction has many advantages: reduced pollution, low costs, and simplicity in process and handling [28]. Herein, we reported a simple and efficient synthesis of 5-arylidene2,4-thiazolidinediones by the Knoevenagel condensation 
TABLE 1: Effect of different reaction conditions on EDDA catalyzed synthesis of 5-benzylidene-2,4-thiazolidinedione ${ }^{\mathrm{a}}$.

\begin{tabular}{|c|c|c|c|c|}
\hline Entry & Temperature $\left({ }^{\circ} \mathrm{C}\right)$ & Catalyst (mol\%) & Time $(\min )$ & Yield $^{\mathrm{b}}(\%)$ \\
\hline 1 & 30 & 10 & 150 & 63 \\
\hline 2 & 40 & 10 & 85 & 77 \\
\hline 3 & 50 & 10 & 35 & 82 \\
\hline 4 & 60 & 10 & 15 & 80 \\
\hline 5 & 70 & 10 & 7 & 90 \\
\hline 6 & 80 & 10 & 3 & 91 \\
\hline 7 & 90 & 10 & 3 & 89 \\
\hline 8 & 80 & - & 3 & - \\
\hline 9 & 80 & 3 & 3 & 76 \\
\hline 10 & 80 & 5 & 3 & 91 \\
\hline 11 & 80 & 20 & 3 & 88 \\
\hline
\end{tabular}

${ }^{a}$ Reaction condition: benzaldehyde ( $\left.10 \mathrm{mmol}\right)$, 2,4-thiazolidinedione (10 mmol), in presence of EDDA under solvent-free conditions.

${ }^{\mathrm{b}}$ Isolated yield.

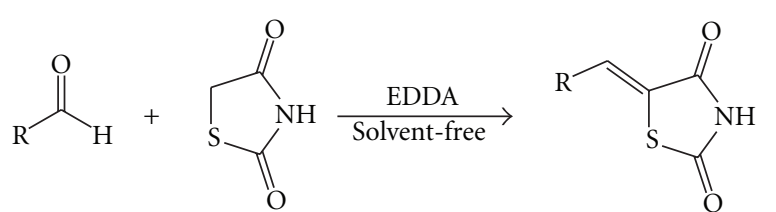

Scheme 1: EDDA catalyzed synthesis of 5-arylidene-2,4-thiazolidinediones.

of aromatic aldehydes with 2,4-thiazolidinedione in the presence of EDDA under solvent-free conditions (Scheme 1).

\section{Results and Discussion}

Initially, benzaldehyde was selected as a probe aldehyde to optimize the reaction conditions, and the results are listed in Table 1. Obviously, the temperature and the amount of catalyst had important effects on the reaction. The mixture was stirred under solvent-free conditions at different temperatures ranging from 30 to $90^{\circ} \mathrm{C}$, with an increment of $10^{\circ} \mathrm{C}$ each time. The yield of 5-benzylidene-2,4-thiazolidinedione was increased and the reaction rate was improved as the reaction temperature was raised from 30 to $80^{\circ} \mathrm{C}$ (Table 1 , entries 1-6). However, raising the reaction temperature from 80 to $90^{\circ} \mathrm{C}$ did not increase the yield and also did not improve the reaction rate (Table 1 , entries 6-7). Therefore, $80^{\circ} \mathrm{C}$ was chosen as the reaction temperature for all further reactions. The optimum amount of EDDA was found to be $5 \mathrm{~mol} \%$ relative to reactants (2,4-thiazolidinedione, $10 \mathrm{mmol}$ and benzaldehyde, $10 \mathrm{mmol}$ ). When the amount of the catalyst decreased to $3 \mathrm{~mol} \%$ from $5 \mathrm{~mol} \%$ relative to the substrates, the yield of 5-benzylidene-2,4-thiazolidinedione was reduced (Table 1, entries 9 and 10). However, the use of $10 \mathrm{~mol} \%$ of the catalyst showed the same yield and the same time was required (Table 1, entries 6 and 10). It is noteworthy that in the absence of a catalyst under the reaction conditions, no product formation was observed after 3 min (Table 1, entry 8). This result indicates that the catalyst exhibits a high catalytic activity in this transformation.
TABLE 2: Recycling of the EDDA for the synthesis of 5-benzylidene2,4-thiazolidinedione ${ }^{\mathrm{a}}$.

\begin{tabular}{lcc}
\hline Run & Time $(\min )$ & Yield $^{\mathrm{b}}(\%)$ \\
\hline 1 & 3 & 91 \\
2 & 3 & 90 \\
3 & 6 & 87 \\
4 & 9 & 86 \\
5 & 14 & 84 \\
\hline
\end{tabular}

Reaction condition: benzaldehyde $(20 \mathrm{mmol}), 2,4$-thiazolidinedione $(20 \mathrm{mmol}), \mathrm{EDDA}(1 \mathrm{mmol})$ at $80^{\circ} \mathrm{C}$ under solvent-free conditions. ${ }^{\mathrm{b}}$ Isolated yield.

From the perspective of green chemistry, it is highly desirable that the catalyst can be recycled. We have also examined the recyclability of EDDA as catalyst by stirring 2,4thiazolidinedione, benzaldehyde and EDDA under solventfree conditions at $80^{\circ} \mathrm{C}$ (Table 2). After the completion of the reaction as monitored by TLC, the reaction mixture was cooled to room temperature and diluted with water. The separated solid was suction filtered, washed with water, and recrystallized from hot ethanol to obtain the pure product. The water containing the EDDA was then evaporated to dryness under reduced pressure and the resulting catalyst was reused directly for the next run. The recovered EDDA can be reused at least four additional times in subsequent reactions without a considerable decrease in catalytic activity.

With these results in hand, we next examined the generality of these conditions to other substrates using several aromatic aldehydes. The results are summarized in Table 3. Several functionalities present in aromatic aldehydes such as halogen, hydroxyl group, methyl group, methoxy, and nitro group were tolerated. In all cases the corresponding 5-arylidene-2,4-thiazolidinediones were obtained in high yields. Cinnamaldehyde and furfural were also successfully converted to corresponding products in high yields. All products obtained are known compounds and were identified by comparing their physical and spectra data with the reported ones. 
TABLE 3: EDDA catalyzed synthesis of 5-arylidene-2,4-thiazolidinediones ${ }^{\mathrm{a}}$.

\begin{tabular}{|c|c|c|c|c|c|c|}
\hline \multirow{2}{*}{ Entry } & \multirow{2}{*}{ Aldehyde } & \multirow{2}{*}{ Product } & \multirow{2}{*}{ Time (min) } & \multirow{2}{*}{ Yield $^{\mathrm{b}}(\%)$} & \multicolumn{2}{|c|}{ M.p. $\left({ }^{\circ} \mathrm{C}\right)$} \\
\hline & & & & & Found & Literature \\
\hline 1 & & & 3 & 91 & $241-242$ & $241-242$ [23] \\
\hline 2 & & & 3 & 88 & $230-232$ & $225-226[23]$ \\
\hline 3 & & & 4 & 91 & $218-220$ & $218-219$ [23] \\
\hline 4 & & & 7 & 89 & $224-225$ & $220-221$ [19] \\
\hline 5 & & & 7 & 84 & $192-194$ & $187-190[5]$ \\
\hline 6 & & & 8 & 79 & $281-282$ & $281[17]$ \\
\hline 7 & & & 40 & 70 & $187-189$ & 185-190 [19] \\
\hline 8 & & & 22 & 91 & $195-197$ & 194 [17] \\
\hline 9 & & & 8 & 82 & $226-228$ & 223-224 [19] \\
\hline 10 & & & $65\left(20^{c}\right)$ & $79\left(90^{c}\right)$ & $213-215$ & 215 [17] \\
\hline 11 & & & $50\left(15^{\mathrm{c}}\right)$ & $74\left(85^{c}\right)$ & $260-262$ & $261-263$ [9] \\
\hline
\end{tabular}


TABle 3: Continued.

Entry

${ }^{\mathrm{a}}$ Reaction condition: aldehyde ( $\left.10 \mathrm{mmol}\right), 2,4$-thiazolidinedione $(10 \mathrm{mmol})$, EDDA $(0.5 \mathrm{mmol})$ at $80^{\circ} \mathrm{C}$ under solvent-free conditions.

${ }^{\mathrm{b}}$ Isolated yield.

${ }^{\mathrm{c}}$ Reactions were carried out at $90^{\circ} \mathrm{C}$.

\section{Conclusion}

In conclusion, we have described a simple and efficient synthesis of 5-arylidene-2,4-thiazolidinediones by the Knoevenagel condensation of aromatic aldehydes with 2,4thiazolidinedione in the presence of ethylenediamine diacetate under solvent-free conditions. The major advantages of this method are simple experimental and work-up procedures, solvent-free reaction conditions, small amount of catalyst, short reaction time, high yields, and utilization of an inexpensive and reusable catalyst.

\section{Experimental}

FT-IR spectra were obtained on a Nexus 470 spectrophotometer. ${ }^{1} \mathrm{H}$ NMR spectra were recorded on a Bruker Avance 400 with TMS as internal standard. Melting points were determined on a melting point apparatus and uncorrected. Thin layer chromatography (TLC) was performed on silica gel F254 plates using a $254 \mathrm{~nm}$ UV lamp or/and iodine vapor to visualize the compounds. 2,4-Thiazolidinedione was prepared according to the literature method [11].

General Procedure for the Preparation of 5-Arylidene2,4-thiazolidinediones. A mixture of 2,4-thiazolidinedione (10 $\mathrm{mmol})$, aldehyde $(10 \mathrm{mmol})$, and EDDA $(0.5 \mathrm{mmol})$ was stirred at $80^{\circ} \mathrm{C}$ in an oil bath for the appropriate time given in Table 3 . The progress of the reaction was monitored by TLC using ethyl acetate/pet ether (1/3) as an eluent. After completion of reaction, the reaction mixture was cooled to room temperature and diluted with water. The separated solid was suction filtered, washed with water, and recrystallized from hot ethanol to obtain the pure product.

\section{Acknowledgment}

The authors thank the Natural Science Foundation of Hubei Province (Grant no. 2007ABA291) for financial support.

\section{References}

[1] M. Oguchi, K. Wada, H. Honma et al., "Molecular design, synthesis, and hypoglycemic activity of a series of thiazolidine2,4-diones," Journal of Medicinal Chemistry, vol. 43, no. 16, pp. 3052-3066, 2000.

[2] M. S. Malamas, J. Sredy, I. Gunawan et al., "New azolidinediones as inhibitors of protein tyrosine phosphatase $\mathrm{lb}$ with antihyperglycemic properties," Journal of Medicinal Chemistry, vol. 43, no. 5, pp. 995-1010, 2000.

[3] R. Murugan, S. Anbazhagan, and S. Sriman Narayanan, "Synthesis and in vivo antidiabetic activity of novel dispiropyrrolidines through $[3+2]$ cycloaddition reactions with thiazolidinedione and rhodanine derivatives," European Journal of Medicinal Chemistry, vol. 44, no. 8, pp. 3272-3279, 2009.

[4] R. Ottanà, R. MacCari, M. L. Barreca et al., "5-Arylidene-2imino-4-thiazolidinones: design and synthesis of novel antiinflammatory agents," Bioorganic and Medicinal Chemistry, vol. 13, no. 13, pp. 4243-4252, 2005.

[5] G. Bruno, L. Costantino, C. Curinga et al., "Synthesis and aldose reductase inhibitory activity of 5-arylidene-2,4-thiazolidinediones," Bioorganic and Medicinal Chemistry, vol. 10, no. 4, pp. 1077-1084, 2002. 
[6] Y. Wu, S. Karna, C. H. Choi et al., "Synthesis and biological evaluation of novel thiazolidinedione analogues as 15-hydroxyprostaglandin dehydrogenase inhibitors," Journal of Medicinal Chemistry, vol. 54, no. 14, pp. 5260-5264, 2011.

[7] N. Zidar, T. Tomašić, R. Šink et al., "Discovery of novel 5-benzylidenerhodanine and 5-benzylidenethiazolidine-2, 4-dione inhibitors of MurD ligase," Journal of Medicinal Chemistry, vol. 53, no. 18, pp. 6584-6594, 2010.

[8] M. A. Ibrahim, M. A. M. Abdel-Hamed, and N. M. El-Gohary, "A new approach for the synthesis of bioactive heteroaryl thiazolidine-2,4-diones," Journal of the Brazilian Chemical Society, vol. 22, no. 6, pp. 1130-1139, 2011.

[9] X. F. Li, Y. Q. Feng, W. H. Zhang, and D. H. Wang, "Synthesis of 3-alkyl-5-benzylidene-2, 4-thiazolidinedione under microwave irradiation," Transactions of Tianjin University, vol. 9, no. 3, pp. 228-230, 2003.

[10] Z. Xia, C. Knaak, M. Jian et al., "Synthesis and evaluation of novel inhibitors of pim-1 and pim-2 protein kinases," Journal of Medicinal Chemistry, vol. 52, no. 1, pp. 74-86, 2009.

[11] S. R. Pattan, P. Kekare, N. S. Dighe et al., "Synthesis and evaluation of some new thiazolidinedione derivatives for their antidiabetic activities," Asian Journal of Research in Chemistry, vol. 2, no. 2, pp. 123-126, 2009.

[12] L. V. Sonawane and S. B. Bari, "Synthesis and spectral characterization of some novel N-substituted 2, 4-thiazolidinedione," International Journal of Biological Chemistry, vol. 5, no. 1, pp. 68-74, 2011.

[13] B. C. C. Cantello, M. A. Cawthorne, G. P. Cottam et al., "[[ $\omega$ (Heterocyclylamino)alkoxy]benzyl]-2,4-thiazolidinediones as potent antihyperglycemic agents," Journal of Medicinal Chemistry, vol. 37, no. 23, pp. 3977-3985, 1994.

[14] S. Mahalle, D. Ligampalle, and R. Mane, "Microwave-assisted synthesis of some 2,4-thiazolidinedione derivatives," Heteroatom Chemistry, vol. 20, no. 3, pp. 151-156, 2009.

[15] M. M. Chowdhry, D. M. P. Mingos, A. J. P. White, and D. J. Williams, "Syntheses and characterization of 5-substituted hydantoins and thiazolines-implications for crystal engineering of hydrogen bonded assemblies. Crystal structures $\mathrm{t}$ of 5-(2-pyridylmethylene)-hydantoin, 5-(2-pyridylmethylene)-2-thiohydantoin, 5-(2-pyridylmethylene)thiazolidine2,4-dione, 5-(2-pyridylmethylene)rhodanine and 5-(2-pyridylmethylene)pseudothiohydantoin," Journal of the Chemical Society, Perkin Transactions 1, no. 20, pp. 3495-3504, 2000.

[16] N. H. Metwally, N. M. Rateb, and H. F. Zohdi, "A simple and green procedure for the synthesis of 5-arylidene-4-thiazolidinones by grinding," Green Chemistry Letters and Reviews, vol. 4, no. 3, pp. 225-228, 2011.

[17] K. F. Shelke, S. B. Sapkal, G. K. Kakade, S. A. Sadaphal, B. B. Shingate, and M. S. Shingare, "Alum catalyzed simple and efficient synthesis of 5-arylidene-2,4-thiazolidinedione in aqueous media," Green Chemistry Letters and Reviews, vol. 3, no. 1, pp. 17-21, 2010.

[18] U. R. Pratap, D. V. Jawale, R. A. Waghmare, D. L. Lingampalle, and R. A. Mane, "Synthesis of 5-arylidene-2,4-thiazolidinediones by Knoevenagel condensation catalyzed by baker's yeast," New Journal of Chemistry, vol. 35, no. 1, pp. 49-51, 2011.

[19] D. H. Yang, B. Y. Yang, Z. C. Chen, and S. Y. Chen, "A convenient synthesis of 5-arylidenethiazolidine-2,4-diones on potassium fluoride-aluminium oxide," Organic Preparations and Procedures International, vol. 38, no. 1, pp. 81-85, 2006.

[20] B. Y. Yang and D. H. Yang, "Solvent-free synthesis of 5benzylidene-2-thioxothiazolidin-4-ones and thiazolidine-2,4diones catalysed by glycine under microwave irradiation," Journal of Chemical Research, vol. 35, no. 4, pp. 238-239, 2011.
[21] S. R. Mahalle, P. D. Netankar, S. P. Bondge, and R. A. Mane, "An efficient method for Knoevenagel condensation: a facile synthesis of 5-arylidenyl 2,4-thiazolidinedione," Green Chemistry Letters and Reviews, vol. 1, no. 2, pp. 103-106, 2008.

[22] K. F. Shelke, S. B. Sapkal, B. R. Madje, B. B. Shingate, and M. S. Shingare, "Ionic liquid promoted an efficient synthesis of 5arylidene-2,4-thiazolidinedione," Bulletin of the Catalysis Society of India, vol. 8, pp. 30-34, 2009.

[23] D. V. Jawale, U. R. Pratap, D. L. Lingampalle, and R. A. Mane, "Dicationic ionic liquid mediated synthesis of 5-arylidine-2,4thiazolidinediones," Chinese Journal of Chemistry, vol. 29, no. 5, pp. 942-946, 2011.

[24] X. Wang and Y. R. Lee, "EDDA-catalyzed rapid synthetic routes for biologically interesting polycycles bearing citrans and chalcones: the first total synthesis of sumadain A," Tetrahedron, vol. 65, no. 49, pp. 10125-10133, 2009.

[25] Y. R. Lee and T. V. Hung, "Ethylenediamine diacetate (EDDA)-catalyzed one-pot synthesis of tetrahydroquinolines by domino Knoevenagel/hetero Diels-Alder reactions from 1,3-dicarbonyls," Tetrahedron, vol. 64, no. 30-31, pp. 73387346, 2008.

[26] Y. R. Lee, H. C. Jung, and H. Y. Sang, "Efficient and general method for the synthesis of benzopyrans by ethylenediamine diacetate-catalyzed reactions of resorcinols with $\alpha, \beta$-unsaturated aldehydes. One step synthesis of biologically active $( \pm)$-confluentin and $( \pm)$-daurichromenic acid," Tetrahedron Letters, vol. 46, no. 44, pp. 7539-7543, 2005.

[27] Y. Hu, Z. C. Chen, Z. G. Le, and Q. G. Zheng, "Organic reactions in ionic liquids: gewald synthesis of 2-aminothiophenes catalyzed by ethylenediammonium diacetate," Synthetic Communications, vol. 34, no. 20, pp. 3801-3806, 2004.

[28] K. Tanaka and F. Toda, "Solvent-free organic synthesis," Chemical Reviews, vol. 100, no. 3, pp. 1025-1074, 2000. 


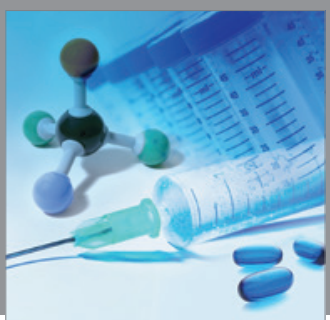

International Journal of

Medicinal Chemistry

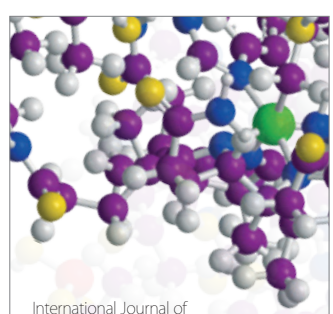

Carbohydrate Chemistry

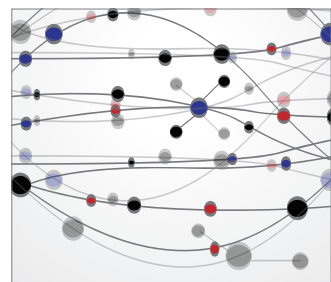

The Scientific World Journal
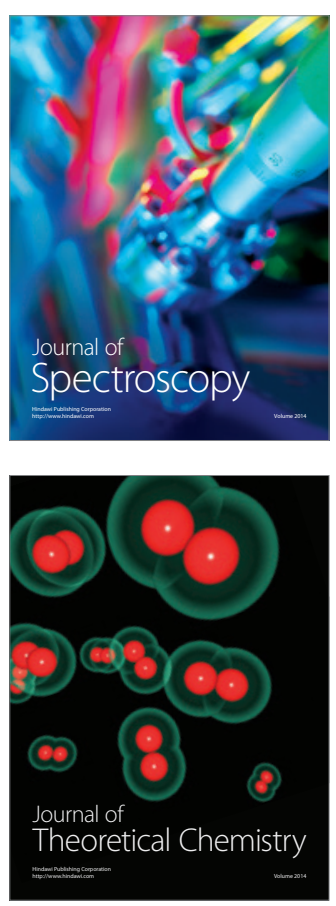
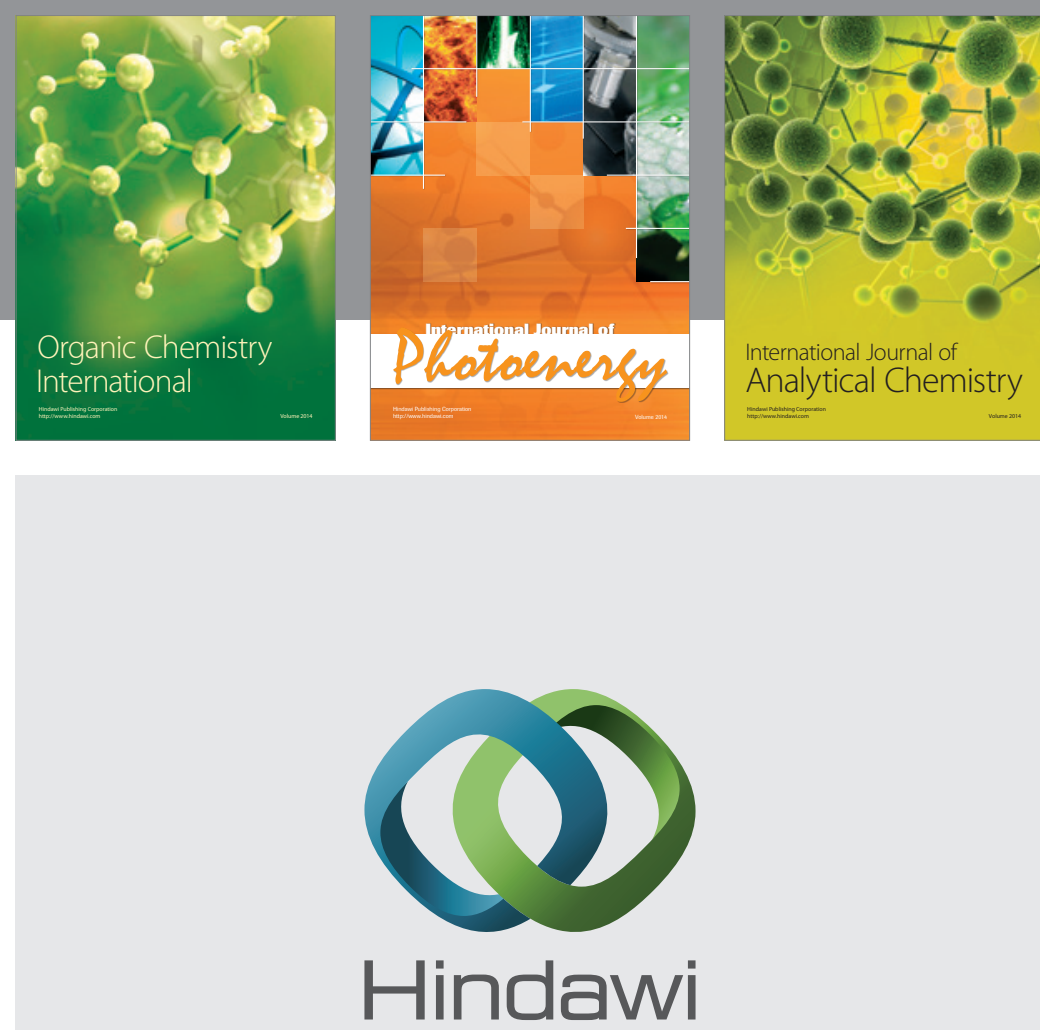

Submit your manuscripts at

http://www.hindawi.com
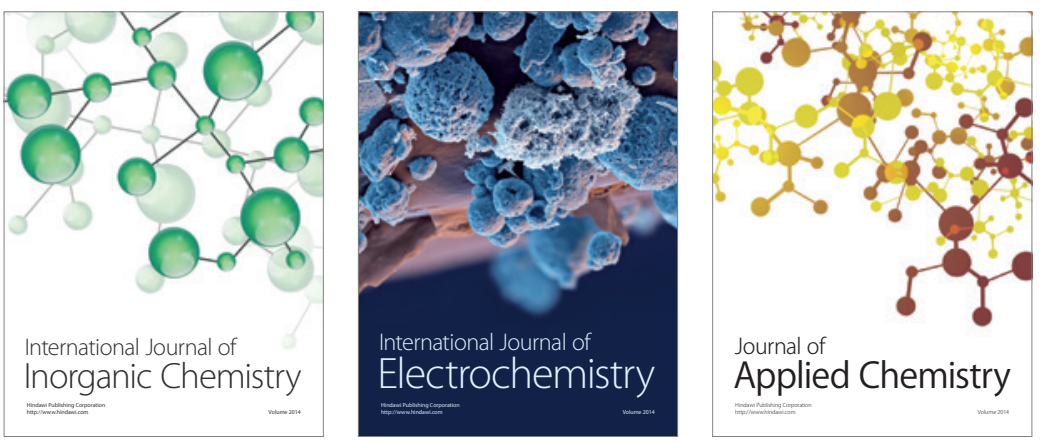

Journal of

Applied Chemistry
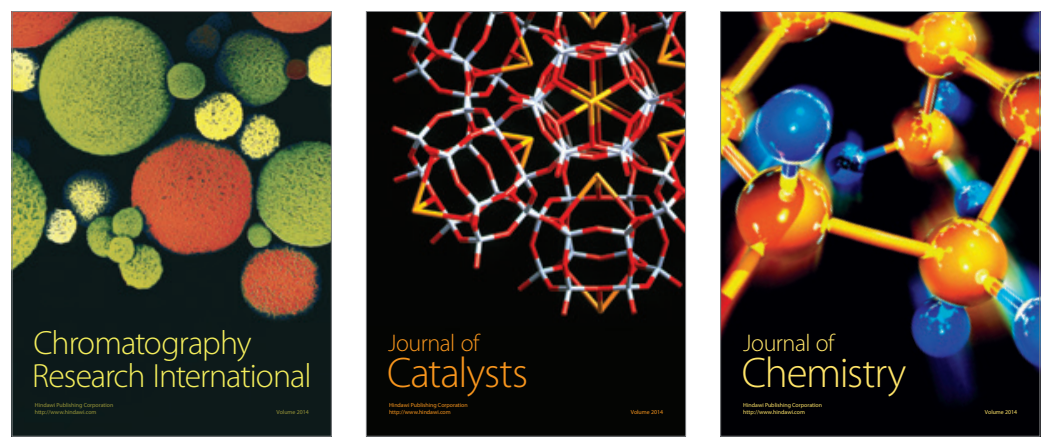
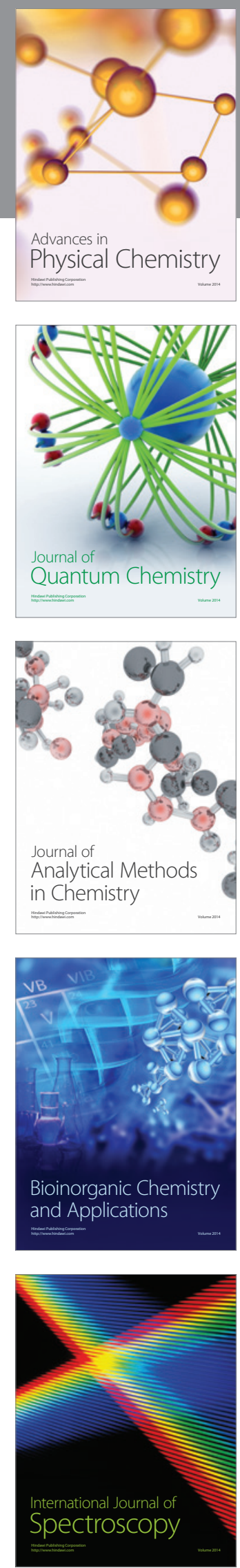